\title{
Bundled payment reimbursement for anterior and posterior approaches for cervical spondylotic myelopathy: an analysis of private payer and Medicare databases
}

\author{
Sohrab S. Virk, MD, MBA, ${ }^{1}$ Frank M. Phillips, MD, ${ }^{2}$ and Safdar N. Khan, MD $^{1}$ \\ 1Department of Orthopaedics, The Ohio State University Wexner Medical Center, Columbus, Ohio; and 2Department of \\ Orthopedic Surgery, Rush University Medical Center, Chicago, Illinois
}

OBJECTIVE Cervical spondylotic myelopathy (CSM) is a progressive spinal condition that often requires surgery. Studies have shown the clinical equivalency of anterior versus posterior approaches for CSM surgery. The purpose of this study was to determine the amount and type of resources used for anterior and posterior surgical treatment of CSM by using large national databases of clinical and financial information from patients.

METHODS This study consists of 2 large cohorts of patients who underwent either an anterior or posterior approach for treatment of CSM. These patients were selected from the Medicare 5\% National Sample Administrative Database (SAF5) and the Humana orthopedic database (HORTHO), which is a database of patients with private payer health insurance. The outcome measures were the cost of a 90 -day episode of care, as well as a breakdown of the cost components for each surgical procedure between 2005 and 2014.

RESULTS A total of 16,444 patients were included in this analysis. In HORTHO, there were 10,332 and 1556 patients treated with an anterior or posterior approach for CSM, respectively. In SAF5, there were 3851 and 705 patients who were treated by an anterior or posterior approach for CSM, respectively. The mean \pm SD reimbursements for anterior and posterior approaches in the HORTHO database were $\$ 20,863 \pm \$ 2014$ and $\$ 23,813 \pm \$ 4258$, respectively $(p=$ 0.048). The mean \pm SD reimbursements for anterior and posterior approaches in the SAF5 database were $\$ 18,219 \pm$ $\$ 1053$ and $\$ 25,598 \pm \$ 1686$, respectively $(p<0.0001)$. There were also significantly higher reimbursements for a rehabilitation/skilled nursing facility and hospital/inpatient care for patients who underwent a posterior approach in both the private payer and Medicare databases. In all cohorts in this study, the hospital-related reimbursement was more than double the surgeon-related reimbursement.

CONCLUSIONS This study provides resource utilization information for a 90 -day episode of care for both anterior and posterior approaches for CSM surgery. There is a statistically significant higher resource utilization for patients undergoing the posterior approach for CSM, which is consistent with the literature. Understanding the reimbursement patterns for anterior versus posterior approaches for CSM will help providers design a bundled payment for patients requiring surgery for CSM, and this study suggests that a subset of patients who require the posterior approach for treatment also require greater resources. The data also suggest that hospital-related reimbursement is the major driver of payments. https://thejns.org/doi/abs/10.3171/2017.7.SPINE1714

KEY WORDS cervical spondylotic myelopathy; anterior approach; posterior approach; resource allocation; bundled payments

ABBREVIATIONS ACDF = anterior cervical discectomy and fusion; CPT = Current Procedural Terminology; CSM = cervical spondylotic myelopathy; DRG = DiagnosisRelated Group; HORTHO = Humana orthopedic database; ICD-9 = International Classification of Diseases, 9th Revision; PSF = posterior spinal fusion; SAF5 = Medicare $5 \%$ National Sample Administrative Database.

SUBMITTED January 4, 2017. ACCEPTED July 6, 2017.

INCLUDE WHEN CITING Published online December 22, 2017; DOI: 10.3171/2017.7.SPINE1714. 


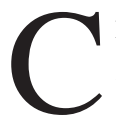
ERVICAL spondylotic myelopathy (CSM) is a progressive spinal disorder that is associated with severe disability. ${ }^{14,18} \mathrm{CSM}$ is the most common spinal cord impairment in adults, and symptoms include gait instability, difficulty with fine motor tasks, weakness, paresthesia, and neck stiffness. ${ }^{14,21}$ There is often a gradual deterioration in function for patients with CSM, although the exact clinical course is highly variable.

There is substantial evidence indicating the benefits of surgery for patients with clinically debilitating CSM. Surgical approaches may involve anterior decompression and fusion or a posterior approach involving decompression with or without fusion. Each approach has specific advantages and disadvantages, and controversy remains in terms of the optimal approach for subgroups of patients. ${ }^{15,16,18,19,23}$ A systematic review by Lawrence et al. did not demonstrate any clear advantage to either the anterior or posterior surgical approach for patients with multilevel CSM. ${ }^{17}$ The authors recommended an individualized approach for patients with CSM based on patient and disease characteristics.

Few data are available regarding the financial implications of the anterior and posterior approaches for CSM. This topic's importance is underscored by the introduction of the Patient Protection and Affordable Care Act and the emphasis placed on cost-effective health care in the current health care environment. ${ }^{3}$ To provide cost-effective health care, there has been a movement away from separate payments for individual services toward a system that provides bundled payments for multiple services during an episode of care (https://innovation.cms.gov/initiatives/ bundled-payments/). With the push toward bundled payments, we aimed to define payments and resource utilization for both anterior and posterior approaches for the treatment of CSM, as well as understand clinical and nonclinical factors that impact reimbursement.

\section{Methods}

The Medicare 5\% National Sample Administrative Database (SAF5) and the Humana orthopedic database (HORTHO) of private payers were both queried to identify patients with cervical myelopathy. We used the PearlDiver software platform (PearlDiver Technologies) to search both databases. Both of these databases have been used extensively across medical specialties to determine treatment patterns across the United States..$^{1,8,11,13}$ These databases include financial and clinical information in the form of International Classification of Diseases, 9th Revision (ICD-9), Current Procedural Terminology (CPT), and Diagnosis-Related Group (DRG) codes with the corresponding financial reimbursements for a large cohort of patients over a number of years. Both of these databases are complementary given the fact that one includes both patients with private insurance and patients receiving health benefits from the government. Furthermore, inclusion of both databases enhances the overall patient population included in our analysis. These databases are compliant with all regulations associated with the Health Insurance Portability and Accountability Act because all patient identifiers were removed from the clinical and fi- nancial data. We used ICD-9 codes to find those patients with CSM. These codes are listed in Table 1. We also used the relevant codes for the anterior and posterior approaches for CSM to find patients who were treated with surgery. The posterior approach-only cohort included patients who underwent an arthrodesis procedure. Patients treated solely with laminectomy or laminoplasty for CSM were not included in our analysis. Relevant CPT codes are also listed in Table 1. All patients who had combined anterior and posterior approaches were excluded from this study.

All clinical and financial information for patients were reviewed starting from the day of the index procedure to 90 days after the index procedure. This time period is based on the definition of a bundled payment by the Centers for Medicare and Medicaid Services. Only anterior or posterior approach surgeries performed in an inpatient setting were included in the study. CPT and DRG codes not related to cervical myelopathy, such as shoulder injections, extremity imaging, and colonoscopies, were excluded from the analysis. CPT codes related to diagnostic imaging and injections were included in the study. CPT and DRG codes that were related to dysphagia, revision/ readmission, neuromonitoring, and rehabilitation services were grouped together for a subgroup analysis (Table 2). HORTHO and SAF5 were queried in an identical manner. Note that HORTHO covers the period from 2007 to 2014, while SAF5 covers the period from 2005 to 2012.

To facilitate comparison between the cohorts of patients treated with either the anterior or posterior approach, we noted the number of levels fused in each cohort. The number of levels fused was estimated for patients who underwent anterior cervical discectomy and fusion (ACDF) using CPT code 22845 (anterior instrumentation of 2-3 levels) and CPT code 22846 (anterior instrumentation of 4-7 segments). The number of levels fused in patients who underwent posterior spinal fusion (PSF) was done by using CPT code 22600 (single-level arthrodesis using a posterior technique), CPT code 22842 (posterior segmental instrumentation of 3-6 vertebral segments), and CPT code 22843 (posterior segmental instrumentation of 7-12 vertebral segments). This query was performed for both SAF5 and HORTHO.

\section{Statistical Significance}

One-way ANOVA was performed to compare costs between the anterior and posterior approaches for CSM. One-way ANOVA was also used to compare average reimbursement for revision/readmission, the intraoperative surgeon, the intraoperative anesthesiologist, rehabilitation, and hospital services between anterior and posterior approaches. The $\mathrm{p}$ values were adjusted using Bonferroni correction.

\section{Results}

A total of 16,444 patients were surgically treated for CSM between 2005 and 2014. HORTHO and SAF5 included 10,332 and 3851 patients treated with an anterior approach for CSM, respectively. HORTHO and SAF5 included 1556 and 705 patients treated with a posterior ap- 
TABLE 1. CPT and ICD-9 codes included in and excluded from the analysis

\begin{tabular}{|c|c|c|}
\hline Code & Description & Included vs Excluded \\
\hline ICD-9-7211 & Cervical spondylosis w/ myelopathy & Included \\
\hline ICD-9-7227 & Intervertebral disc disorder w/ myelopathy & Included \\
\hline ICD-9-72271 & Cervical disc disease w/ myelopathy & Included \\
\hline СРT-22554 \& CPT-22551 & $\begin{array}{l}\text { Arthrodesis \& anterior interbody technique, including minimal } \\
\text { discectomy to prepare the interspace (other than for decom- } \\
\text { pression); cervical below C-2 segment }\end{array}$ & Anterior included \\
\hline CPT-63075 & Anterior cervical discectomy & Anterior included \\
\hline CPT-22590 \& CPT-22595 & Arthrodesis \& posterior technique & Posterior included \\
\hline CPT-22600 & $\begin{array}{l}\text { Single-level arthrodesis \& posterior or posterolateral tech- } \\
\text { nique; cervical below C-2 segment }\end{array}$ & Posterior included \\
\hline $\begin{array}{l}\text { CPT-96401, CPT-96402, CPT-96405, CPT-96406, } \\
\text { CPT-96411, CPT-96420, CPT-96422, CPT-96423, } \\
\text { CPT-96425, CPT-96440, CPT-96446, CPT-96450, } \\
\text { CPT-96542, CPT-96549, ICD-9-1400, \& ICD-9-23999 }\end{array}$ & $\begin{array}{l}\text { ICD-9 \& CPT codes associated with cancer, including CPT } \\
\text { codes for chemotherapy, ICD-9 codes for neoplasm, \& } \\
\text { medication administration }\end{array}$ & Excluded \\
\hline ICD-9-D-80000 to ICD-9-D-83999 & ICD -9 codes related to trauma & Excluded \\
\hline
\end{tabular}

proach for CSM, respectively. Demographic information is included in Table 3. The most frequently reimbursed CPT codes for each approach to CSM are listed in Tables 4 and 5. The most frequently reimbursed CPT codes were similar between SAF5 and HORTHO data sets.

Total reimbursements for SAF5 and HORTHO were significantly different between the anterior and posterior approaches for treatment of CSM. The mean \pm SD reimbursements for the anterior and posterior approaches in SAF5 were $\$ 18,219 \pm \$ 1053$ and $\$ 25,598 \pm \$ 1686$, respectively $(\mathrm{p}<0.001)$. The mean $\pm \mathrm{SD}$ reimbursements for the anterior and posterior approaches in HORTHO were $\$ 20,863 \pm \$ 2014$ and $\$ 23,813 \pm \$ 4258$, respectively $(\mathrm{p}=0.048)$. There was no significant difference in SAF5 reimbursement between sexes for either the anterior procedure (mean $\$ 18,837$ for men and $\$ 17,826$ for women; $p$ $=0.74$ ) or the posterior procedure (mean $\$ 25,502$ for men and $\$ 26,969$ for women; $p=0.84$ ). Similarly, there was no difference in HORTHO reimbursement between sexes for either the anterior procedure (mean \$20,274 for men and $\$ 20,918$ for women; $p=0.98$ ) or the posterior procedure (mean $\$ 24,012$ for men and $\$ 23,790$ for women; $p=0.99$ ).

A separate analysis was performed to determine reim- bursement for each procedure when performed in patients of different ages. We grouped those patients as younger than 65 years or 65 years and older. The mean \pm SD reimbursement for an anterior procedure in the SAF5 cohort administered to elderly patients was $\$ 19,224 \pm \$ 929$, while the reimbursement for those younger than 65 years was $\$ 17,881 \pm \$ 1310$. This difference only approached significance $(p=0.067)$. This same trend of higher reimbursement for elderly patients was also observed for posterior procedures in the SAF5 cohort (mean \pm SD $\$ 26,958 \pm$ $\$ 1190$ for elderly patients vs $\$ 24,140 \pm \$ 2984$ for younger patients; $p=0.057)$. There was, however, higher reimbursement noted for younger patients in the HORTHO cohort for the anterior procedure (mean \pm SD $\$ 17,027 \pm$ $\$ 1597$ for elderly patients vs $\$ 22,530 \pm \$ 2539 ; \mathrm{p}=0.001)$. The same pattern was seen in patients in the HORTHO cohort who underwent the posterior procedure (mean \pm SD $\$ 21,688 \pm \$ 98$ for elderly patients vs $\$ 27,627 \pm \$ 1331$ for younger patients; $\mathrm{p}=0.002$ ).

A detailed analysis was performed to analyze the proportions of reimbursement for different aspects of care (Tables 6 and 7). Hospital reimbursement accounted for the overwhelming majority of payments regardless of pay-

TABLE 2. Proportion of CPT codes listed for dysphagia, readmission/revision procedures, and neuromonitoring

\begin{tabular}{cccc}
\hline \multicolumn{1}{c}{ Purpose } & \multicolumn{1}{c}{ Relevant CPT Codes } & Relevant DRG Codes & Description of Select CPT \& DRG Codes \\
\hline $\begin{array}{l}\text { Dysphagia } \\
\text { related }\end{array}$ & CPT-43235, CPT-43248, CPT- & DRG-182, DRG-392, \& DRG- & CPT-43235 = upper gastrointestinal endoscopy; CPT-92611 \\
& 43239, CPT-92611, CPT-74230, & 641 & $\begin{array}{c}\text { motion fluoroscopic evaluation of swallowing function } \\
\text { by cine or video recording; DRG-392 = esophagitis }\end{array}$ \\
\hline $\begin{array}{c}\text { Readmission/ } \\
\text { revision }\end{array}$ & CPT-99281, CPT-99282, CPT- & DRG-452, DRG-872, DRG- & CPT-99281 = emergency department visit for the evaluation \\
& 99283, CPT-99284, CPT-99285, & 857, DRG-921, DRG-690, & \& management of a patient; DRG-418 = postop \& post- \\
& CPT-99291, CPT-99292, CPT- & DRG-871, DRG-920, DRG- & traumatic infection \\
& 99238, CPT-99239, CPT-99253, & 641, DRG-468, DRG-477, & \\
& \& CPT-99254 & DRG-443, \& DRG-418 & \\
\hline Neuromonitoring & CPT-95920, CPT-95925, CPT- & & CPT-95920 = intraop neurophysiology testing; CPT-95927 = \\
& 95926, \& CPT-95927 & & short-latency somatosensory evoked potential study \\
\hline
\end{tabular}


TABLE 3. Patient demographics of the anterior and posterior cohorts of patients in SAF5 and HORTHO

\begin{tabular}{lrrrr}
\hline Characteristic & $\begin{array}{c}\text { Anterior } \\
\text { SAF5 }\end{array}$ & $\begin{array}{c}\text { Anterior } \\
\text { HORTHO }\end{array}$ & $\begin{array}{c}\text { Posterior } \\
\text { SAF5 }\end{array}$ & $\begin{array}{r}\text { Posterior } \\
\text { HORTHO }\end{array}$ \\
\hline Sex & & & & \\
\hline Male & 50.84 & 51.36 & 59.94 & 61.18 \\
\hline Female & 49.16 & 48.64 & 40.06 & 38.82 \\
\hline Age in yrs & & & & \\
\hline$<65$ & 37.00 & 55.59 & 21.43 & 33.44 \\
\hline $65-69$ & 29.10 & 20.27 & 27.43 & 24.48 \\
\hline $70-74$ & 17.72 & 14.21 & 22.57 & 19.74 \\
\hline $75-79$ & 10.37 & 6.79 & 13.71 & 13.18 \\
\hline $80-84$ & 4.36 & 2.42 & 11.00 & 6.62 \\
\hline$\geq 85$ & 1.45 & 0.71 & 3.86 & 2.53 \\
\hline Geographic region & & & & \\
\hline Midwest & 19.49 & 19.84 & 23.97 & 28.73 \\
\hline Northeast & 10.82 & 1.62 & 22.84 & 2.44 \\
\hline South & 51.89 & 69.69 & 37.45 & 59.58 \\
\hline West & 17.80 & 8.86 & 15.74 & 9.25 \\
\hline
\end{tabular}

All values are shown as the percentage of patients.

er or surgical approach. There was a higher proportion of reimbursement spent on rehabilitation or skilled nursing facilities after posterior surgery. The proportion of reimbursement attributed to the surgeon was similar between anterior and posterior approaches. The proportion of reimbursement for revision/readmission-related care for either approach ranged from $2.30 \%$ to $5.54 \%$. The revision/ reoperation rates for the anterior and posterior approaches for patients in the SAF5 database were $1.71 \%$ and $2.98 \%$, respectively $(\mathrm{p}=0.023)$. The revision rates for anterior and posterior approaches for patients in the HORTHO database were $2.35 \%$ and $2.89 \%$, respectively $(\mathrm{p}=0.196)$.

Given the significant differences in reimbursement between the anterior and posterior approaches for CSM, a breakout analysis was performed to compare reimbursement per patient for the top 5 most reimbursed aspects of care. These are listed in Tables 8 and 9. The hospital reimbursement per inpatient was significantly higher for the posterior approach for both the SAF5 and HORTHO cohorts. Surgeon reimbursement was significantly higher for the posterior approach than for the anterior approach in the SAF5 cohort (mean difference \$487), but was similar in the HORTHO cohort.

The number of levels fused was estimated using the CPT codes for each cohort of patients, and these results are outlined in Table 10. Of note, given the nature of the CPT code definitions, a direct comparison of the number of levels fused in the anterior and posterior cohorts is not possible. In both cohorts, however, there is a large majority of patients with fewer than 5 levels of fusion.

\section{Discussion}

This study identified a breakdown of payments for anterior and posterior surgical approaches in the treatment of CSM. Resource utilization was significantly different for patients undergoing an anterior or posterior approach for CSM. In patients undergoing a posterior approach for CSM, higher payments were made for hospital/inpatient services, revision/readmission services, and rehabilitation/ skilled nursing facility care.

The finding of higher third-party payments for the treatment of patients undergoing a posterior approach is consistent with the previously reported literature. ${ }^{17-19}$ Our findings are supported by those of Shamji et al., who showed that resource utilization was significantly higher for patients undergoing a posterior approach for diffuse cervical spondylosis. ${ }^{23}$ In the current study, we did not separate fusion from nonfusion posterior procedures, which could impact the rates of reimbursement. This study, however, provides a unique insight into how resource utilization differs between these treatment options. We caution that in addition to considering cost efficiency, clinical factors, including the location of neural compression, number of levels involved in causing CSM, and sagittal alignment, must be considered when deciding on a specific surgical approach in a given patient. ${ }^{9}$ Previous studies in the literature have shown that the complication rate associated with posterior surgery is higher than that associated with anterior surgery for CSM. ${ }^{4}$ Our study found higher rates of payment for revision/readmission-related DRG/CPT codes after a posterior approach than after an anterior ap-

TABLE 4. Top 5 CPT codes and proportion of total reimbursement for anterior approaches in the SAF5 database

\begin{tabular}{|c|c|c|c|c|}
\hline Rank & СРТ & Description & Reimbursement & $\begin{array}{l}\text { Percentage of Total } \\
\text { Reimbursement }\end{array}$ \\
\hline 1 & CPT-63075 & $\begin{array}{l}\text { Anterior discectomy w/ decompression of spinal cord \&/or nerve root(s), including } \\
\text { osteophytectomy; single cervical interspace }\end{array}$ & $\$ 2,391,961$ & 3.41 \\
\hline 2 & CPT-22845 & Anterior instrumentation; $2-3$ vertebral segments & $\$ 1,829,035$ & 2.61 \\
\hline 3 & CPT-22554 & $\begin{array}{l}\text { Arthrodesis \& anterior interbody technique, including minimal discectomy to pre- } \\
\text { pare interspace (other than for decompression); cervical below C-2 segment }\end{array}$ & $\$ 1,627,725$ & 2.32 \\
\hline 4 & CPT-22551 & $\begin{array}{l}\text { Arthrodesis \& anterior interbody technique, including disc space preparation, } \\
\text { discectomy, osteophytectomy, \& decompression of spinal cord \&/or nerve } \\
\text { roots; cervical below C-2 segment }\end{array}$ & $\$ 1,559,406$ & 2.22 \\
\hline 5 & CPT-22851 & $\begin{array}{l}\text { Application of intervertebral biomechanical device(s), e.g., synthetic cage(s), } \\
\text { threaded bone dowel(s), methylmethacrylate, to vertebral defect or interspace }\end{array}$ & $\$ 1,227,189$ & 1.75 \\
\hline
\end{tabular}


TABLE 5. Top 5 CPT codes and proportion of total reimbursement for posterior approaches

\begin{tabular}{|c|c|c|c|c|}
\hline Rank & CPT & Description & Reimbursement & $\begin{array}{l}\text { Percentage of Tota } \\
\text { Reimbursement }\end{array}$ \\
\hline \multicolumn{5}{|l|}{ SAF5 } \\
\hline 1 & CPT-22614 & Single-level arthrodesis \& posterior or posterolateral technique & $\$ 621,439$ & 3.43 \\
\hline 2 & CPT-22600 & Single-level arthrodesis \& posterior or posterolateral technique; below C-2 segment & $\$ 561,508$ & 3.10 \\
\hline 3 & CPT-22842 & $\begin{array}{l}\text { Posterior segmental instrumentation (e.g., pedicle fixation, dual rods w/ multiple } \\
\text { hooks \& sublaminar wires); 3-6 vertebral segments }\end{array}$ & $\$ 362,836$ & 2.00 \\
\hline 4 & CPT-63045 & $\begin{array}{l}\text { Laminectomy, facetectomy, \& foraminotomy (unilateral or bilateral w/ decompres- } \\
\text { sion of spinal cord, cauda equina, \&/or nerve roots [e.g., spinal or lateral recess } \\
\text { stenosis]); single vertebral segment; cervical }\end{array}$ & $\$ 300,324$ & 1.66 \\
\hline 5 & CPT-00670 & $\begin{array}{l}\text { Anesthesia for extensive spine \& spinal cord procedures (e.g., spinal instrumenta- } \\
\text { tion or vascular procedures) }\end{array}$ & $\$ 253,805$ & 1.40 \\
\hline \multicolumn{5}{|c|}{ HORTHO } \\
\hline 1 & CPT-22600 & Single-level arthrodesis \& posterior or posterolateral technique below C-2 segment & $\$ 1,877,910$ & 5.07 \\
\hline 2 & CPT-22614 & $\begin{array}{l}\text { Single-level arthrodesis \& posterior or posterolateral technique (each additional } \\
\text { vertebral segment is listed separately in addition to the code for the primary } \\
\text { procedure) }\end{array}$ & $\$ 1,862,623$ & 5.03 \\
\hline 3 & CPT-22842 & $\begin{array}{l}\text { Posterior segmental instrumentation (e.g., pedicle fixation, dual rods w/ multiple } \\
\text { hooks \& sublaminar wires); 3-6 vertebral segments }\end{array}$ & $\$ 1,163,015$ & 3.14 \\
\hline 4 & CPT-00670 & $\begin{array}{l}\text { Anesthesia for extensive spine \& spinal cord procedures (e.g., spinal instrumenta- } \\
\text { tion or vascular procedures) }\end{array}$ & $\$ 1,012,676$ & 2.73 \\
\hline 5 & CPT-63045 & $\begin{array}{l}\text { Laminectomy, facetectomy, \& foraminotomy (unilateral or bilateral w/ decompres- } \\
\text { sion of spinal cord, cauda equina, \&/or nerve roots [e.g., spinal or lateral recess } \\
\text { stenosis]); single vertebral segment; cervical }\end{array}$ & $\$ 948,754$ & 2.56 \\
\hline
\end{tabular}

proach (\$999/patient vs \$419/patient in SAF5 and \$1320/ patient vs \$638/patient in HORTHO). This pattern of reimbursement was consistent between both the HORTHO and SAF5 cohorts.

A significant limitation to our study, however, is the lack of information from a claims database regarding the degree of myelopathy associated with a patient undergoing either an anterior or posterior approach for CSM. Therefore, our results, in regard to increased resource utilization for patients undergoing a posterior approach, may reflect worse preoperative symptoms in this group. These

TABLE 6. Breakdown of reimbursement proportions of various aspects of care for ACDF

\begin{tabular}{lrr}
\hline \multicolumn{1}{c}{ Aspect of Care } & SAF5 & HORTHO \\
\hline $\begin{array}{l}\text { Hospital/inpatient services, including inpatient } \\
\text { hospitalization, inpatient lab tests, \& inpatient } \\
\text { imaging }\end{array}$ & 68.07 & 58.95 \\
\hline $\begin{array}{l}\text { Intraop surgeon } \\
\text { Rehabilitation/skilled nursing care facility }\end{array}$ & 17.27 & 26.25 \\
\hline Revision/readmission \& emergency department & 2.30 & 5.01 \\
\hline Intraop anesthesiology & 2.13 & 3.06 \\
\hline $\begin{array}{l}\text { Outpatient services, including clinic visits \& } \\
\quad \text { outpatient imaging }\end{array}$ & 1.72 & 1.00 \\
\hline Neuromonitoring & 0.77 & 1.70 \\
\hline Dysphagia-related treatment & 0.16 & 0.15 \\
\hline
\end{tabular}

All values are shown as the percentage of patients. patients very likely required more extensive decompression/fusion procedures and thus had a higher overall reimbursement rate and usage of skilled nursing facilities. While we acknowledge this limitation, our findings are still relevant, as they provide support for increased reimbursement for patients requiring a more expensive posterior surgery due to their clinical symptoms. Any designers of future bundled payments for CSM surgical treatment will need to consider these findings when designing reimbursement figures.

There has been increased scrutiny of surgeon-related

TABLE 7. Breakdown of reimbursement proportions of various aspects of care for posterior approaches

\begin{tabular}{lcc}
\hline \multicolumn{1}{c}{ Aspect of Care } & SAF5 & HORTHO \\
\hline $\begin{array}{l}\text { Hospital/inpatient services, including inpatient } \\
\text { hospitalization, inpatient lab tests, \& inpatient } \\
\text { imaging }\end{array}$ & 59.45 & 57.65 \\
\hline Intraop surgeon & 14.14 & 22.03 \\
\hline Rehabilitation/skilled nursing care facility & 18.81 & 9.47 \\
\hline Revision/readmission \& emergency department & 3.89 & 5.54 \\
\hline Intraop anesthesiology & 1.83 & 3.29 \\
\hline $\begin{array}{l}\text { Outpatient services, including clinic visits \& } \\
\quad \text { outpatient imaging }\end{array}$ & 0.99 & 0.63 \\
\hline Neuromonitoring & 0.81 & 1.32 \\
\hline Dysphagia-related treatment & 0.09 & 0.07 \\
\hline
\end{tabular}

All values are shown as the percentage of patients. 
TABLE 8. Reimbursements for ACDF and the posterior approach for patients in SAF5

\begin{tabular}{|c|c|c|c|}
\hline Aspect of Care & ACDF* $^{*}$ & Posterior* & p Value \\
\hline Hospital/inpatient services, including inpatient hospitalization, inpatient lab tests, \& inpatient imaging & $\$ 12,392 \pm 657$ & $\$ 15,260 \pm 411$ & 0.0045 \\
\hline Intraop surgeon & $\$ 3,144 \pm 60$ & $\$ 3,631 \pm 95$ & 0.005 \\
\hline Rehabilitation/skilled nursing care facility & $\$ 1,379 \pm 166$ & $\$ 4,828 \pm 309$ & $<0.0001$ \\
\hline Intraop anesthesiology & $\$ 388 \pm 24$ & $\$ 469 \pm 12$ & 0.0005 \\
\hline Revision/readmission \& emergency department & $\$ 419 \pm 18$ & $\$ 999 \pm 120$ & 0.018 \\
\hline
\end{tabular}

* Values are shown as the mean \pm SD reimbursement per patient.

reimbursement, although an overall lowering in surgeon reimbursement when adjusted for inflation over the previous decade has been reported., ${ }^{2,12,22}$ In the current study, surgeon reimbursement ranged from $14 \%$ to $26 \%$ of overall reimbursement. This is in contrast to the proportion of reimbursement for hospital-related care, which ranged from $57 \%$ to $68 \%$. Given the significantly higher portion of reimbursement for hospital-related charges, it would seem that strategies that influence hospital-related payments and incentives would have a far greater impact on overall health care spending. This finding is similar to that in work done by Molina et al., who showed that the proportion of billing for surgeons for lumbar laminectomy accounted for $23 \%$ to $30 \%$ of overall billing. ${ }^{22}$ We defined the episode of care to include the day of the index procedure to 90 days after the index procedure. This time period is consistent with that previously defined by the Centers for Medicare and Medicaid Services. ${ }^{7}$ This would be the likely time period covered by a bundled payment, and the study defines the dollar amounts of payment as well as the breakdown of payments by services provided.

Previous research on bundled payments for total joint replacement demonstrated the significant portion of reimbursement allocated to rehabilitation/skilled nursing facility services, and our study demonstrates this pattern for patients undergoing treatment for CSM. ${ }^{6,20}$ Postacute services accounted for more than $18 \%$ of total reimbursement for Medicare patients after undergoing the posterior approach for treatment of CSM. The relatively high expense for postacute services in this cohort will need to be considered in a future bundled payment for CSM treatment. In a study by Froemke et al., claims for total hip/ knee replacement were reduced by $6 \%$ by implementing initiatives including reducing the number of patients discharged to a skilled nursing facility. ${ }^{10}$

As with all other large database studies that rely on
CPT, ICD-9, and DRG codes for physician and hospital billing, there are weaknesses associated with this study related to discrepancies between claims databases and patient chart reviews. ${ }^{5}$ It is impossible for us to confirm the accuracy of each diagnosis or procedure. Hospitals and providers, however, have a vested interest in accurately portraying charges for third-party payers to avoid fraud allegations and to be appropriately compensated for their work. This study did not include reimbursement figures for prescription medications, which would underestimate total reimbursement. Due to the fact that hospital reimbursement was based on DRG reimbursement, we are unable to further delineate how hospital reimbursement is divided among different patient services.

Within our cohort of CSM patients in the SAF5 database, there was a higher than expected rate of patients who were younger than 65 years. Patients younger than 65 years represented $37 \%$ and $21.43 \%$ of patients in the anterior and posterior SAF5 cohorts, respectively. This cohort of patients younger than 65 years and receiving Medicare coverage has high rates of end-stage renal disease, amyotrophic lateral sclerosis, mental health disorders, cancer, and other disorders that make them sicker than the typical population of patients under 65 years. ${ }^{7} \mathrm{We}$, therefore, expected reimbursement to be higher for those patients younger than 65 years. Our data, however, showed lower reimbursement for those patients younger than 65 years. This may be due to the progressive nature of CSM, and the patients who waited until they were older may have had worse symptomatology.

We only included patients who underwent an arthrodesis procedure for the treatment of CSM in our posterior cohort. This limited the scope of our analysis because we did not include those patients who are treated for CSM solely with laminectomy/laminoplasty. This was done because anterior approaches are performed with an as-

TABLE 9. Reimbursements for ACDF and the posterior approach for patients in HORTHO

\begin{tabular}{|c|c|c|c|}
\hline Aspect of Care & ACDF* $^{*}$ & Posterior* & p Value \\
\hline Hospital/inpatient services, including inpatient hospitalization, inpatient lab tests, \& inpatient imaging & $\$ 12,280 \pm 194$ & $\$ 13,725 \pm 171$ & 0.0015 \\
\hline Intraop surgeon & $\$ 5,469 \pm 151$ & $\$ 5,246 \pm 267$ & 0.32 \\
\hline Rehabilitation/skilled nursing care facility & $\$ 1,044 \pm 394$ & $\$ 2,256 \pm 199$ & 0.0043 \\
\hline Intraop anesthesiology & $\$ 809 \pm 15$ & $\$ 782 \pm 6$ & 0.0125 \\
\hline Revision/readmission \& emergency department & $\$ 638 \pm 141$ & $\$ 1,320 \pm 322$ & $<0.0001$ \\
\hline
\end{tabular}

* Values are shown as the mean \pm SD reimbursement per patient. 
TABLE 10. Number of levels fused in each cohort of patients

\begin{tabular}{cc}
\hline Number of Levels Fused & \\
\hline HORTHO & Percentage \\
\hline No. of levels fused in ACDF & \\
\hline $1-2$ & 78.60 \\
\hline 3 & 21.39 \\
\hline No. of levels fused in PSF & 14.43 \\
\hline 1 & 76.55 \\
\hline $2-5$ & 9.03 \\
\hline 26 & \\
\hline SAF5 & 79.77 \\
\hline No. of levels fused in ACDF & 20.23 \\
\hline $1-2$ & \\
$\geq 3$ & 12.21 \\
\hline No. of levels fused in PSF & 78.49 \\
\hline 1 & 9.30 \\
\hline $2-5$ &
\end{tabular}

* Given limitations of CPT code descriptions, only a range of fused levels can be provided.

sociated arthrodesis and any comparison with a posterior surgery without fusion would not be difficult. Further research is required regarding a bundled payment centered around cervical laminoplasty/laminectomy.

We have also refrained from direct comparisons between SAF5 and HORTHO given the inherent differences in their cohorts (e.g., regional variations, age, comorbidities). This can be seen within Table 3, as the SAF5 cohort was in general older and had a higher proportion of patients from the northeastern United States. We caution direct comparison between the 2 cohorts given the baseline differences in their makeup. Future designs of bundled payments will also need to take into account these inherent differences in each database when creating reimbursement estimates for CSM patients requiring operative treatment.

\section{Conclusions}

Our study shows significantly higher resource utilization for posterior approach surgery for the treatment of CSM than for anterior approach surgery. The proportion of reimbursement for skilled nursing facility/rehabilitation, inpatient/hospital services, and revision/readmission services was higher for those patients undergoing a posterior approach. In all cohorts within this study, hospitalrelated reimbursement was nearly double the surgeon-related reimbursement, thereby reflecting the importance of hospital-directed efforts to curb costs.

\section{References}

1. Bala A, Huddleston JI III, Goodman SB, Maloney WJ, Amanatullah DF: Venous thromboembolism prophylaxis after tka: aspirin, warfarin, enoxaparin, or factor Xa inhibitors? Clin Orthop Relat Res 475:2205-2213, 2017

2. Berven S, Smith A, Bozic K, Bradford DS: Pay-for-perfor- mance: considerations in application to the management of spinal disorders. Spine (Phila Pa 1976) 32 (11 Suppl):S33S38, 2007

3. Berwick DM, Hackbarth AD: Eliminating waste in US health care. JAMA 307:1513-1516, 2012

4. Boakye M, Patil CG, Santarelli J, Ho C, Tian W, Lad SP: Cervical spondylotic myelopathy: complications and outcomes after spinal fusion. Neurosurgery 62:455-462, 2008

5. Bozic KJ, Chiu VW, Takemoto SK, Greenbaum JN, Smith TM, Jerabek SA, et al: The validity of using administrative claims data in total joint arthroplasty outcomes research. J Arthroplasty 25 (6 Suppl):58-61, 2010

6. Bozic KJ, Ward L, Vail TP, Maze M: Bundled payments in total joint arthroplasty: targeting opportunities for quality improvement and cost reduction. Clin Orthop Relat Res 472:188-193, 2014

7. Cubanski J, Neuman T, Damico A: Medicare's role for people under 65 with disabilities. Kaiser Family Foundation. August 12, 2016. (http://www.kff.org/medicare/issue-brief/ medicares-role-for-people-under-age-65-with-disabilities/) [Accessed September 13, 2017]

8. Deitelzweig S, Luo X, Gupta K, Trocio J, Mardekian J, Curtice T, et al: Comparison of effectiveness and safety of treatment with apixaban vs. other oral anticoagulants among elderly nonvalvular atrial fibrillation patients. Curr Med Res Opin 33:1745-1754, 2017

9. Fehlings MG, Barry S, Kopjar B, Yoon ST, Arnold P, Massicotte EM, et al: Anterior versus posterior surgical approaches to treat cervical spondylotic myelopathy: outcomes of the prospective multicenter AOSpine North America CSM study in 264 patients. Spine (Phila Pa 1976) 38:2247-2252, 2013

10. Froemke CC, Wang L, DeHart ML, Williamson RK, Ko LM, Duwelius PJ: Standardizing care and improving quality under a bundled payment initiative for total joint arthroplasty. $\mathbf{J}$ Arthroplasty 30:1676-1682, 2015

11. Grisdela P Jr, Buser Z, D’Oro A, Paholpak P, Liu JC, Wang JC: Trends analysis of surgical procedures for cervical degenerative disc disease and myelopathy in patients with tobacco use disorder. Eur Spine J, 2017

12. Hariri S, Bozic KJ, Lavernia C, Prestipino A, Rubash HE: Medicare physician reimbursement: past, present, and future. J Bone Joint Surg Am 89:2536-2546, 2007

13. Hess LM, Louder A, Winfree K, Zhu YE, Oton AB, Nair R: Factors associated with adherence to and treatment duration of erlotinib among patients with non-small cell lung cancer. $\mathbf{J}$ Manag Care Spec Pharm 23:643-652, 2017

14. Kalsi-Ryan S, Singh A, Massicotte EM, Arnold PM, Brodke DS, Norvell DC, et al: Ancillary outcome measures for assessment of individuals with cervical spondylotic myelopathy. Spine (Phila Pa 1976) 38 (22 Suppl 1):S111-S122, 2013

15. Karadimas SK, Erwin WM, Ely CG, Dettori JR, Fehlings MG: Pathophysiology and natural history of cervical spondylotic myelopathy. Spine (Phila Pa 1976) 38 (22 Suppl 1):S21-S36, 2013

16. Komotar RJ, Mocco J, Kaiser MG: Surgical management of cervical myelopathy: indications and techniques for laminectomy and fusion. Spine J 6 (6 Suppl):252S-267S, 2006

17. Lawrence BD, Jacobs WB, Norvell DC, Hermsmeyer JT, Chapman JR, Brodke DS: Anterior versus posterior approach for treatment of cervical spondylotic myelopathy: a systematic review. Spine (Phila Pa 1976) 38 (22 Suppl 1):S173-S182, 2013

18. Lebl DR, Bono CM: Update on the diagnosis and management of cervical spondylotic myelopathy. J Am Acad Orthop Surg 23:648-660, 2015

19. Liu B, Ma W, Zhu F, Guo CH, Yang WL: Comparison between anterior and posterior decompression for cervical spondylotic myelopathy: subjective evaluation and cost analysis. Orthop Surg 4:47-54, 2012 
20. London DA, Vilensky S, O'Rourke C, Schill M, Woicehovich L, Froimson MI: Discharge disposition after joint replacement and the potential for cost savings: effect of hospital policies and surgeons. J Arthroplasty 31:743-748, 2016

21. Matz PG, Anderson PA, Holly LT, Groff MW, Heary RF, Kaiser MG, et al: The natural history of cervical spondylotic myelopathy. J Neurosurg Spine 11:104-111, 2009

22. Molina CA, Zadnik PL, Gokaslan ZL, Witham TF, Bydon A, Wolinsky JP, et al: A cohort cost analysis of lumbar laminectomy-current trends in surgeon and hospital fees distribution. Spine J 13:1434-1437, 2013

23. Shamji MF, Massicotte EM, Traynelis VC, Norvell DC,

Hermsmeyer JT, Fehlings MG: Comparison of anterior surgical options for the treatment of multilevel cervical spondylotic myelopathy: a systematic review. Spine (Phila Pa 1976) 38 (22 Suppl 1):S195-S209, 2013

\section{Disclosures}

The authors report no conflict of interest concerning the materi- als or methods used in this study or the findings specified in this paper.

\section{Author Contributions}

Conception and design: all authors. Acquisition of data: Virk. Analysis and interpretation of data: all authors. Drafting the article: Virk. Critically revising the article: all authors. Reviewed submitted version of manuscript: all authors. Approved the final version of the manuscript on behalf of all authors: Khan. Statistical analysis: Virk. Study supervision: Khan.

\section{Supplemental Information}

Previous Presentations

This work was presented in abstract form at the 44th Meeting of the Cervical Spine Research Society, Toronto, Ontario, Canada, December 1-3, 2016.

\section{Correspondence}

Safdar N. Khan, Department of Orthopaedics, The Ohio State University, 725 Prior Hall, 376 W Tenth St., Columbus, OH 43210. email: safdar.khan@osumc.edu. 